\title{
Searching for Molecular Abnormalities in Genetic Diseases by the Use of a Double Labeling Technique. II. Deficiency of a Basic Protein in Fibroblasts of Patients with Pompe's Disease
}

\author{
S. D. J. PENA, ${ }^{(23)}$ N. M. QUILLIAM, J. L. HAMERTON, AND K. WROGEMANN \\ Department of Pediatrics (Genetics) and Biochemistry, University of Manitoba, Winnipeg, Manitoba, Canada
}

\begin{abstract}
Summary
We used a double labeling technique to search for molecular defects in two fibroblast strains obtained from patients with Pompe's disease. Analysis of the double labeled subcellular fractions by sodium dodecyl sulfate (SDS) electrophoresis did not reveal any abnormalities except in the "mitochondrial-lysosomal" fraction. In this fraction ratio deviations indicated that in Pompe's disease there was a significant decrease in counts of a protein with molecular weight of about 29,000 . After solubilization by freezethawing this protein was shown to have an isoelectric point of 7.9 in contrast to the $\alpha$-glucosidase which focused at about $\mathrm{pH}$ 4.7. Two-stage gel studies demonstrated an estimated $90 \%$ reduction of this protein in Pompe's disease. Two-stage studies of acid $\alpha$ glucosidase did not show any abnormal ratios of leucine incorporation. Similar although quantitatively less pronounced results were obtained in the study of skin fibroblasts from a patient with adult glycogen storage disease type II.
\end{abstract}

\section{Speculation}

The deficient basic protein with minimum molecular weight of 29,000 is structurally unrelated to acid glucosidase and represents a "new" molecular defect in type II glycogenosis.

Pompe's disease, also known as glycogen storage disease type II (GSD II) was first described in 1932 by Pompe (15). The disease is characterized by generalized glycogen accumulation manifesting as hepatomegaly, profound hypotonia and massive enlargement of the heart with failure. In its typical infantile form Pompe's disease is uniformly lethal in the first year of life. In 1963 Hers (7) demonstrated very reduced activity of lysosomal acid $\alpha$-glucosidase (acid maltase, EC 3.2.1.20) in the tissues of affected infants. More recently several groups have described milder forms of acid $\alpha$-glucosidase deficiency constituting the so-called late infantile, juvenile (childhood), and adult forms of GSD II $(4,8,9)$. In the adult form clinical manifestations are generally restricted to muscle weakness, often producing a picture similar to limb-girdle muscular dystrophy (3).

We considered Pompe's disease a good model for testing our double labeling procedure (14) because a basic biochemical defect is known (acid $\alpha$-glucosidase deficiency) and the disease is expressed in cultured skin fibroblasts (8). Moreover, acid maltase has lysosomal localization and its isoelectric point (18) and molecular weight $(1,18)$ are known although there are still questions as to the structure of the human enzyme (1). However, when we began these studies we were unaware that many authors have questioned, based on pathological and biochemical observations, whether this enzyme is the single or primary genetic defect in GSD II $(6,10,16,19)$.

\section{MATERIALS AND METHODS}

Human skin fibroblast strains GM103, GM495 (normal control subjects), GM248 (Pompe's disease), and GM443 (adult GSD II) were obtained from the Institute for Medical Research, Camden, $\mathrm{NJ}$, and strains $\mathrm{McH} 12$ (normal control subject) and WG482 (Pompe's disease patient) were obtained from the Repository for Mutant Human Cell Strains, Montreal, Quebec. The procedures used for cell culturing and labeling, cell fractionation, polyacrylamide gel electrophoresis in the presence of sodium dodecyl sulfate (SDS-PAGE), isoelectric focusing (IEF), assay of radioactivity in gels, and analysis and plotting of data have been described in detail elsewhere (14), $\alpha-1,4-$ Glucosidase was assayed in fibroblast lysates with 4 -methylumbelliferyl- $\alpha$-glucopyranoside (Sigma) as substrate by the method of Fujimoto et al. (5). Staining for the enzyme in IEF gels was done according to the method of Salafsky and Nadler (17). Protein was assayed by the method of Lowry et al. (11) with bovine serum albumin as standard.

\section{RESULTS}

\section{$\alpha$-GLUCOSIDASE ASSAYS}

To test whether the strains obtained from the cell repositories were indeed deficient in acid $\alpha$-glucosidase activity the enzyme was assayed in lysates. Fibroblast strains from patients with Pompe's disease (GM248, WG482) had close to zero activity while the cell strain obtained from an adult GSD II patient (GM443) showed approximately $25 \%$ residual activity of $\alpha$-glucosidase.

\section{MACROMOLECULAR MAPPING}

SDS-PAGE of double labeled subcellular fractions of normal control and Pompe's disease fibroblasts did not reveal any anomalies except in the "mitochondrial-lysosomal" (ML) fraction, where there was indication of a molecular abnormality in a minor protein peak with an apparent molecular weight of approximately 29,000 . When the ML fraction was submitted to repeated cycles of freezing and thawing the "defect" was found in the solubilized (ML-S) portion (Fig. 1). The particulate localization of this defective fraction, its solubilization by freezing and thawing, and the molecular weight of approximately 29,000 (the subunit molecular weight for the bovine liver acid glucosidase is approximately $26,000(2))$ were all compatible with the possibility that the "defective" protein was acid maltase. However, analysis by IEF showed an abnormal ratio at approximately pI 7.9 rather than at pI 4.7 where the acid glucosidase could be detected by enzymatic staining. No glucosidase activity (acid or neutral) could be detected at pI 7.9 in patients or control subjects. The abnormal ratios were reproducible both by "inverting" the labels and using another control strain (Fig. 2) and by using a second fibroblast strain from 


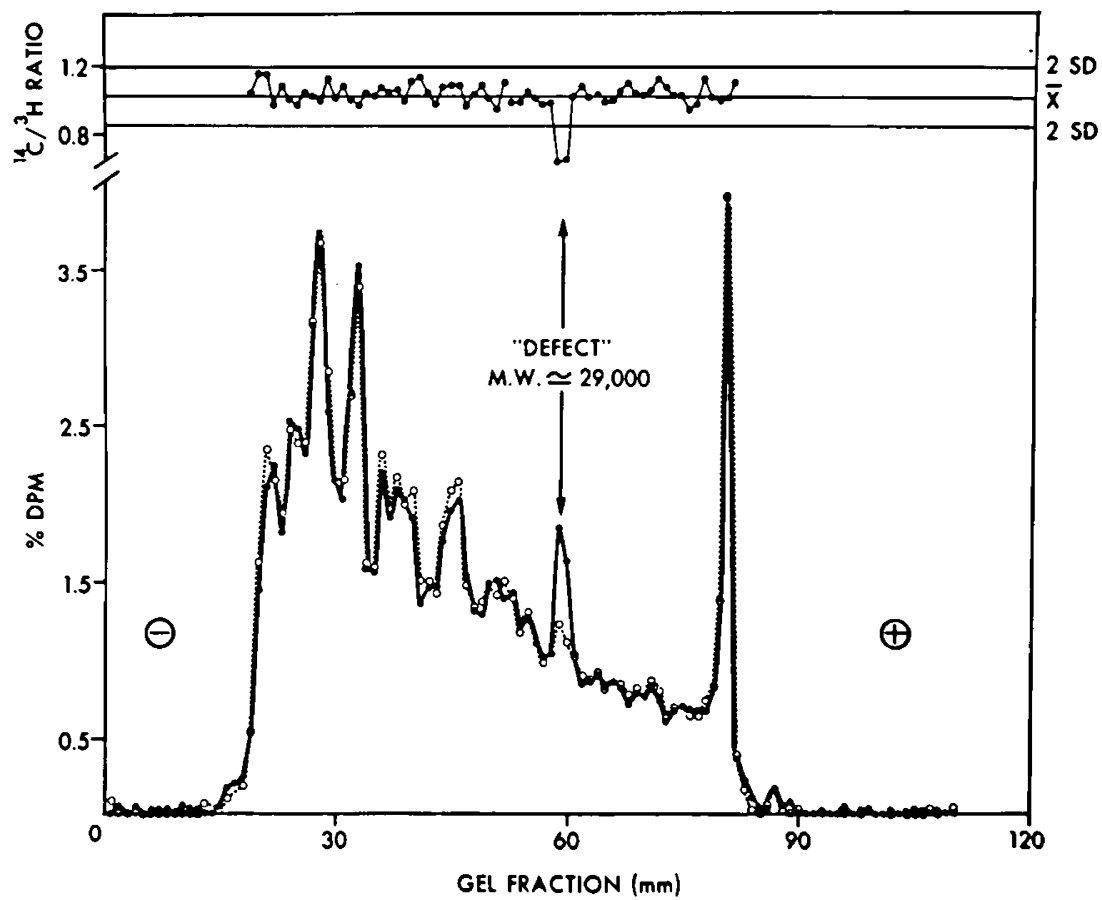

Fig. 1. Plot of an SDS-PAGE gel indicating a decrease of a protein fraction in Pompe's disease. Fibroblast strain GM103 (normal control subject) was labeled with $\left[{ }^{3} \mathrm{H}\right]$ leucine $(-\infty)$ and strain GM248 (Pompe's disease patient) was labeled with $\left[{ }^{14} \mathrm{C}\right]$ leucine $(0 \cdots O)$ as described in the text. Cells from both strains were combined, homogenized, and fractionated by differential centrifugation. The ML pellet was suspended in $5 \mathrm{mM}$ Tris, 2 mM EDTA, 5 mM 2-mercaptoethanol (pH 7.0), submitted to five cycles of freezing and thawing, and respun. The supernatant (ML-S) was submitted to SDS electrophoresis in a $13 \%$ acrylamide gel.

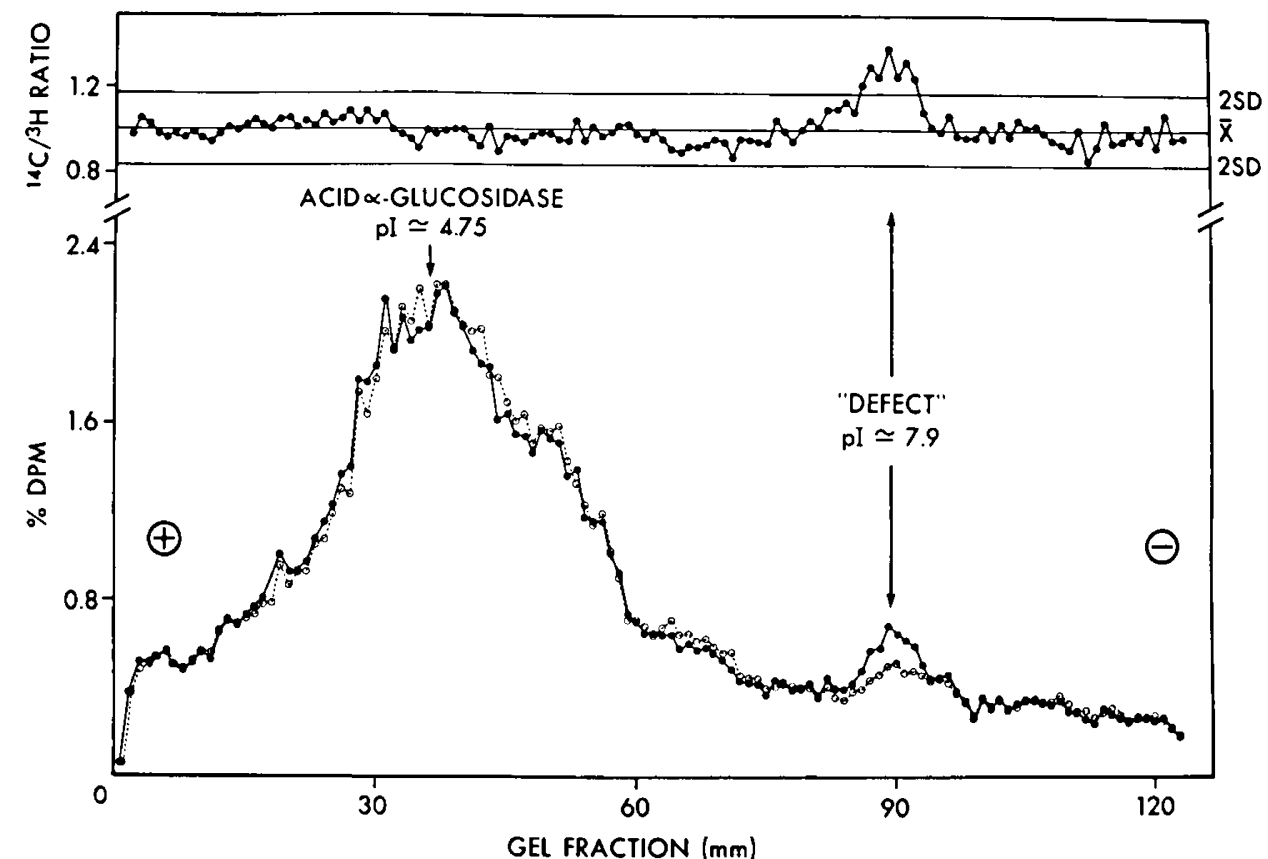

Fig. 2. Plot of isoelectric focusing gel indicating decrease of a basic protein fraction in Pompe's disease. Fibroblast strain GM186 (normal control subject) was labeled with $\left[{ }^{14} \mathrm{C}\right]$ leucine $(\longrightarrow)$ and strain GM248 (Pompe's disease patient) was labeled with $\left[{ }^{3} \mathrm{H}\right] l$ leucine $(\mathrm{O} \cdots \mathrm{O})$. The ML-S fraction was prepared and submitted to IEF in presence of $\mathrm{pH}$ 3.5-10 ampholines. Note that labels are "inverted" in comparison to Figures 1 and 3.

another patient with Pompe's disease. It remained to be proven that the "defective" regions in SDS-PAGE and IEF were due to the same protein fraction. Two-stage mapping performed by doing SDS-PAGE of the abnormal fraction from an IEF gel showed a single peak again with an apparent molecular weight of 29,000 in which there was a marked decrease in the label associated with Pompe's disease (Fig. 3a). If the high "baseline" observed in this plot is averaged and subtracted, roughly a $90 \%$ reduction of label in Pompe's disease can be estimated by integrating the area under the peaks. In contrast, SDS-PAGE of the acid glucosidase band from IEF did not reveal any obvious abnormality (Fig. $3 b$ ). It was concluded that a basic protein fraction with minimum molecular weight of 29,000 was markedly deficient in infantile cases of GSD II. To test whether this deficiency is a general feature of GSD II and not an exclusive feature of infantile cases, strain GM443 (adult GSDII) was studied. IEF of the double labeled ML-S 

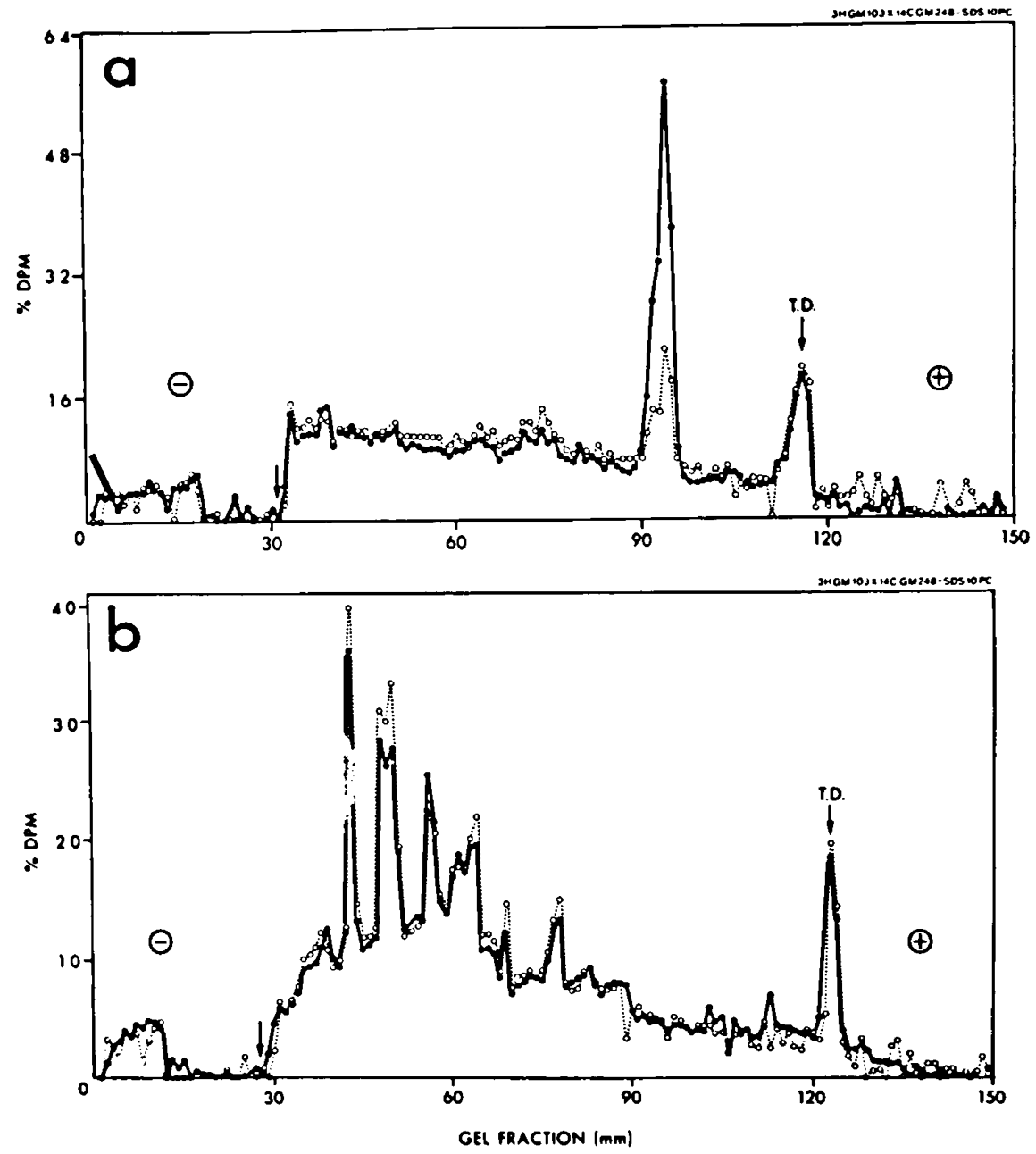

Fig. 3. SDS-PAGE (13\%) of "defect" $(a)$ and acid glucosidase $(b)$ regions of IEF gel of fraction ML-S of a double labeled mixture of ${ }^{14} \mathrm{C}$-leucinelabeled Pompe's disease fibroblasts (GM248, O ..O) and ${ }^{3} \mathrm{H}$-leucine-labeled normal control fibroblasts (GM103, —— — T. D. indicates the tracking dye area.

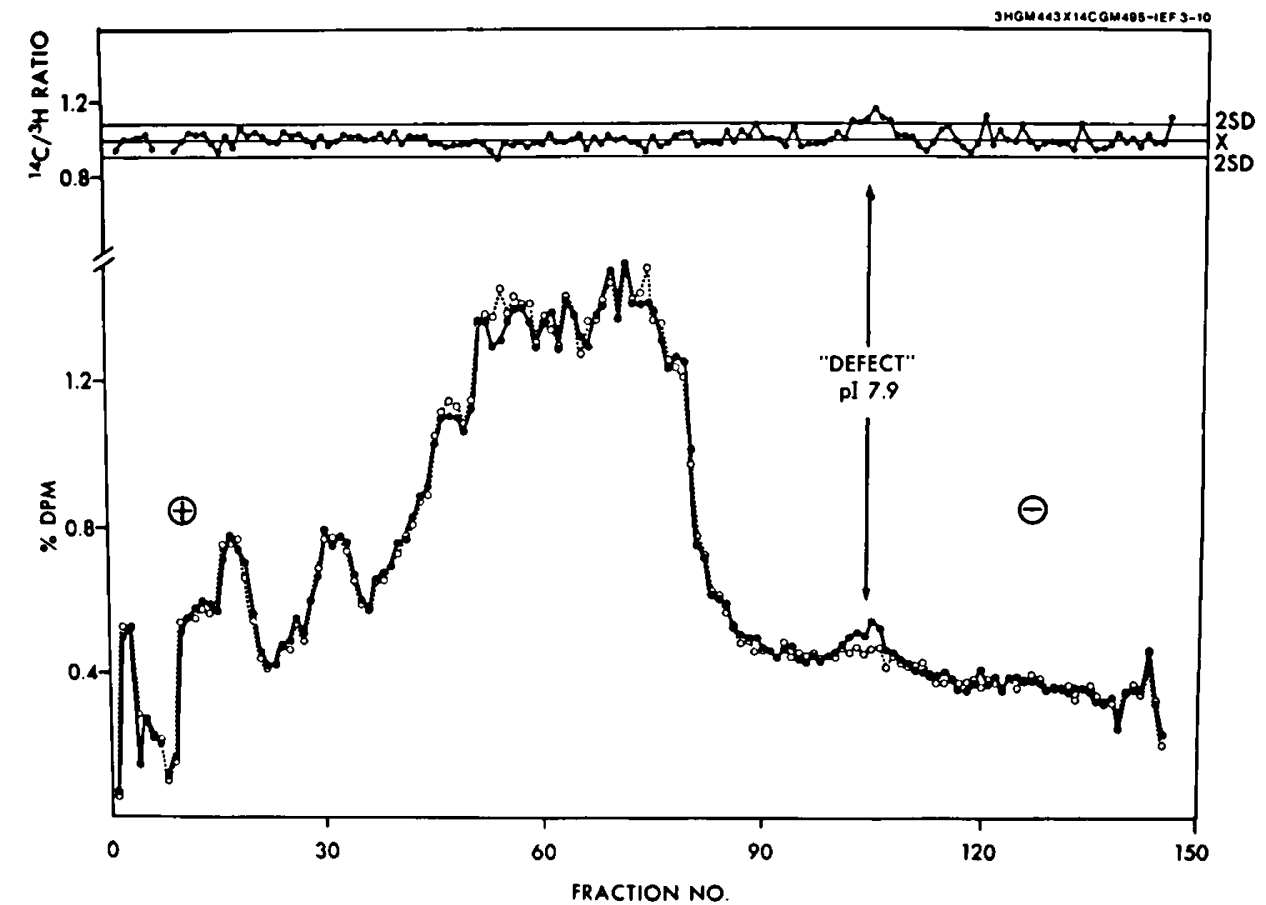

Fig. 4. IEF gel of fraction ML-S of a double labeled mixture of ${ }^{3} \mathrm{H}$-leucine-labeled adult GSD II fibroblasts $(\mathrm{GM} 443, \mathrm{O} \cdots \mathrm{O})$ and ${ }^{14} \mathrm{C}-\mathrm{leucine}-$ labeled normal control fibroblasts (GM495, 
fraction again showed deficiency of a basic protein (Fig. 4). Second stage analysis of this "defect" showed a decrease of a 29,000 molecular weight component in GSD II (Fig. 5a). The decrease in label was smaller than the one seen in the infantile cases. SDS-PAGE of the acid glucosidase region from IEF again showed no abnormalities (Fig. $5 b$ ).

\section{DISCUSSION}

The delineated deficiency of a basic protein fraction with minimum apparent molecular weight of approximately 29,000 in Pompe's disease cannot be readily explained. Noteworthy is the fact that by using the double labeling technique a molecular defect with the characteristics of $\alpha$-glucosidase could not be detected, even in two-stage mapping. This suggests that either a type II error (14) is being made (missing the defect) or that the acid maltase molecules of GSD II patients do not differ much in turnover, charge, or molecular weight from the normal enzyme. The fact that the "defect" observed in the basic protein fraction was caused by a deficiency of label associated with Pompe's disease rather than an excess rules out the possibility that it was caused by an acid maltase with altered isoelectric point.

Logically, if two correlated observations, say A and B, have been made, one of the following four situations must prevail: 1) A $=B$; 2) a third event $C$, causes both A and B; 3) A causes B; 4) B causes $A$. In three fibroblast strains from patients with GSD II two observations have been made: deficient acid maltase activity (A) and deficiency of a basic protein fraction (B). We will analyze these observations in the light of the above four alternatives:
1) $\mathrm{A}=\mathrm{B}$. A structural model might be envisaged in which native acid glucosidase was partially dissociated into its component units during IEF. In this case the basic component might represent an acid maltase subunit. This model is not in agreement with current knowledge of acid maltase structure, mainly because the dissociation of the enzyme occurs only in the presence of strong chaotropic agents; moreover, the enzyme subunits are insoluble in aqueous buffers $(1,2)$. However, it would be desirable to check the deficient basic protein fraction for cross-reactivity with antiglucosidase antibodies.

2) $C$ causes both $A$ and $B$. In this case neither acid maltase deficiency nor the molecular defect delineated here would be the primary defect in Pompe's disease, but merely secondary to a third defect which might interfere with their "realization" (13). Alternatively, and less likely, a regulatory gene mutation might be envisaged in Pompe's disease determining the deficiency of two different proteins.

3) A causes B. It might also be that events secondary to acid glucosidase deficiency, e.g., glycogen accumulation, lysosomal proliferation, etc., could possibly lead to decreased synthesis or increased degradation of other protein components, such as the one described.

4) B causes A. Finally, the reverse of the previous alternative might occur, i.e., the deficient basic protein described above might be the primary defect and secondarily lead to deficiency of acid glucosidase activity. Such might occur, for instance, if the deficient protein were an activator of acid maltase. Protein activators have been described for different lysosomal sphingolipid hydrolases (12). Preliminary experiments involving mixing fibroblast lysates
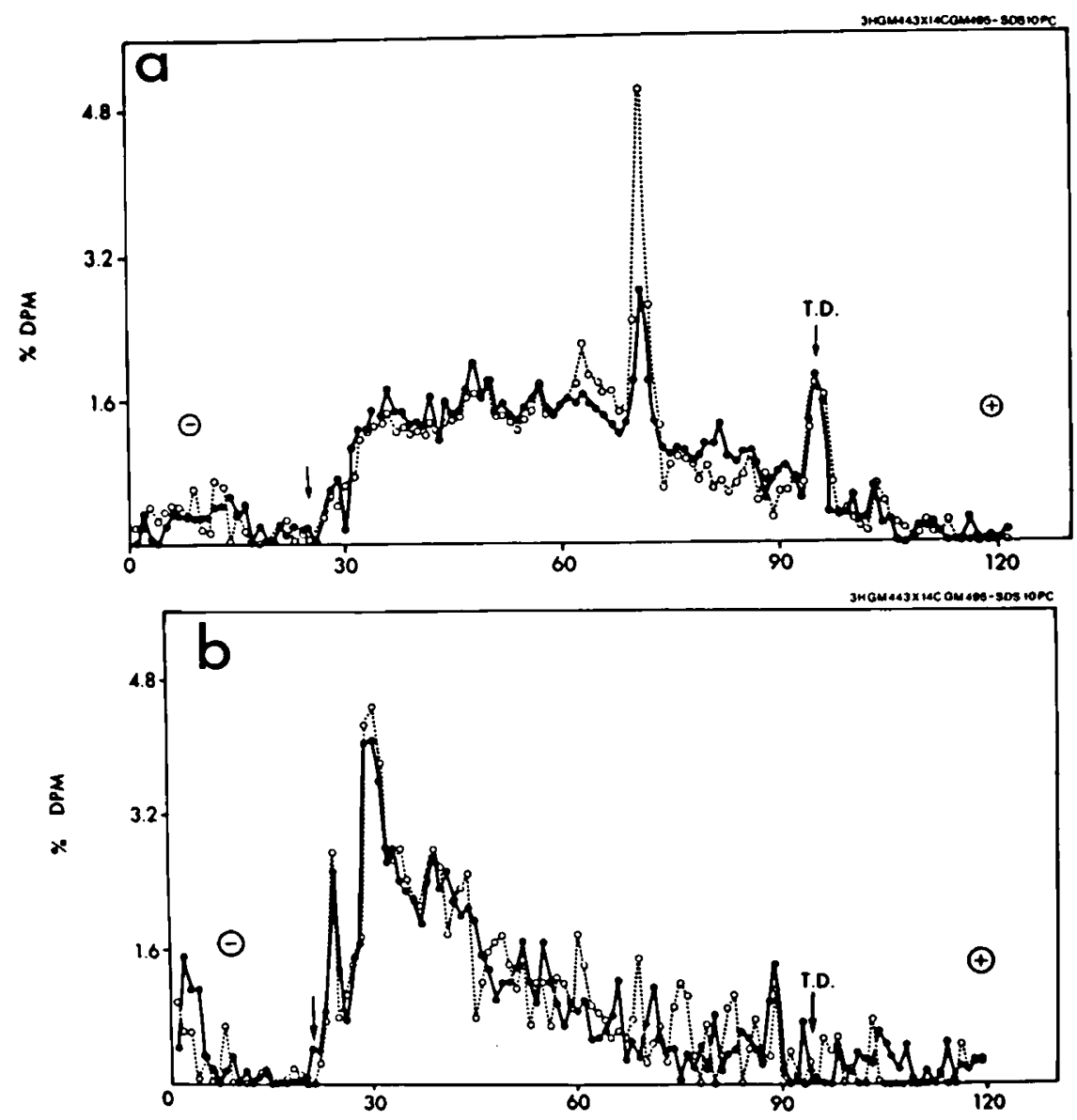

GEL FRACTION

Fig. 5. SDS-PAGE (13\%) of "defect" $(a)$ and acid glucosidase (b) regions of IEF gel of fraction ML-S of a double labeled mixture of ${ }^{3} \mathrm{H}-\mathrm{leucine}-$ labeled adult GSD II fibroblasts (GM443, - $\longrightarrow$ ) and ${ }^{14} \mathrm{C}$-leucine-labeled normal control fibroblasts (GM495, $O \cdots O$ ). The high variability observed in most of plot $b$ is due to low counts. T.D. indicates the tracking dye region of the gel. 
from normal control subjects and patients with Pompe's disease have already been performed in our laboratory but, so far, no latent acid maltase activity has been detected in Pompe's disease.

\section{CONCLUSION}

No final conclusion can be reached yet on the significance of the reported findings. However, the point should be made that by using a double labeling technique we have been able to define a discrete molecular abnormality, apparently structurally unrelated to acid glucosidase, in a particulate fraction of skin fibroblasts from patients with Pompe's disease. This abnormality may represent a "new" molecular defect in Pompe's disease. It was expressed as a significant ratio deviation that fits all previously defined criteria for abnormality (14): the abnormal ratio corresponds to a discrete peak in SDS-PAGE and IEF gels; it was observed in three GSD II fibroblast strains, and it persisted when the labels were reversed. We feel that these findings are evidence of the usefulness of the double labeling technique in the investigation of the molecular pathology of inherited diseases, particularly of its ability to uncover unsuspected anomalies.

\section{REFERENCES AND NOTES}

I. Belenki. D. M., and Rosenfeld. E. L.: Acid a-glucosidase ( $r$-amylase) from human liver. Clin. Chim. Act2, 60: 397 (1975).

2. Bruni, C. B., Sica, V. Auricchio. F., and Covelli, 1.: Further kinetic and structural characterization of the lysosomal $a$-D-glucoside glucohydrolase from cattle liver. Biochim. Biophys. Acta, 2/2: 470 (1970).

3. Carrier, H., Lebel, M., Mathieu, M., Pialat, J., and Davic, M.: Late familial pseudo-myopathic muscular glycogenosis with alpha-1,4-glucosidase deficiency. Pathol. Eur., 10: 51 (1975).

4. Engel, A. G., Gomez, M. R., Seybold, M. E., and Lambert, E. H.: The spectrum and diagnosis of acid maltase deficiency. Neurology, 23: 95 (1973).

5. Fujimoto, A., Fluharty, A. L., Stevens, R. L., Kihara, H., and Wilson, M. G.: Two alpha-glucosidases in cultured amniotic fluid cells and their differentia. tion in the prenatal diagnosis of Pompe's disease. Clin. Chim. Acta, 68: 177 (1976).

6. Garancis, J. C.: Type II glycogenosis-Biochemical and electron microscopy study. Amer. J. Med. 44: 289 (1968).

Copyright $\odot 1978$ International Pediatric Research Foundation, Inc. 0031 -3998/78/1209-0894502.00/0
7. Hers, H. G.: a-Glucosidase deficiency in generalized glycogen-storage disease (Pompe's disease). Biochem. J., 86: 111 (1963).

8. Hers, H. G., and de Barsy, T.: Type II glycogenosis (acid maltase deficiency). In: H. G. Hers and F. vanHoof: Lysosomes and Storage Diseases (Academic Press, New York, 1973).

9. Hers, H. G., and vanHoof, F.: Glycogen storage diseases: Type II and type VI glycogenosis. In F. Dickens, J. Randle, and W. J. Whelam: Carbohydrate Metabolism and Its Disorders, Vol. II (Academic Press, New York, 1968).

10. Hug. G., Schubert. W. K., and Soukoup. S.: Treatment related observations in solid tissues, fibroblast cultures and amniotic fluid cells of Type II glycogenosis. Hurler disease and metachromatic leukodystrophy. Birth Defects: Origina! Aricle Series, Vol. IX. No. 2. p. 160, 1973.

11. Lowry, O. H., Rosebrough. A. L.. Farr. A. L., and Randall. R. J.: Protein measurement with the Folin phenol reagent. J. Biol. Chem.. 193: 265 (1951).

12. Mraz, W. Fischer, G., and Jatkewitz, H.: Low molecular weight proteins in secondary lysosomes as activators of different sphingolipid hydrolases. FEBS Lett., 67: 104 (1976).

13. Paigen, K.: The genetics of enzyme realization. In: M. Rechcigl: Enzyme Synthesis and Degradation in Mammalian Systems (Karger, Basel, 1971).

14. Pena, S. D. J., and Wrogemann, K.: Searching for molecular abnormalities in genetic diseases by the use of a double labeling technique. I. Rationale, methods and initial evaluation. Pediat. Res., 12: 894 (1978).

15. Pompe, J. -C.: Hypertrophic idiopathique du coeur. Ann. Anat. Pathol., 10: 23 (1933).

16. Rowland, L. P., DiMauro, S., and Bank. W. J.: Glycogen storage diseases of muscle-problems in biochemical genetios. Birth Defects: Original Article Series, Vol. VII. No. 2. p. 43. 1971.

17. Salafsky, I. S., and Nadler. H. L.: Deficiency of acid alpha-glucosidase in the urine of patients with Pompe's disease. J. Pediat. 82: 294 (1973).

18. Swallow, D. M., Corney, G., and Harris, H.: Acid $\alpha$-glucosidase: A new polymorphism in man demonstrable by "affinity electrophoresis." Ann. Hum. Genet., 38: 391 (1975).

19. Wolfe, H. J., and Cohen, R. B.: Nonglycogen polysaccharide storage in glycogenosis type II. Arch. Pathol., 86: 579 (1968).

20. This research was supported by the Muscular Dystrophy Association of Canada. The Manitoba Heart Foundation, The Mrs. J. A. Richardson Foundation, and The Medical Research Council.

21. Dr. S. D. J. Pena is a posidoctoral fellow of the Medical Research Council of Canada.

22. We are grateful to Dr. M. C. Blanchaer and Dr. J. H. Wang for stimulating discussion.

23. Requests for reprints should be addressed to: Dr. S. D. J. Pena. Montreal Neurological Institute, Montreal. Quebec H3A 2B4 (Canada).

24. Received for publication June 1. 1977.

25. Accepted for publication November 16. 1977. 